\title{
Estimating Sex of Modern Greeks Based on the Foramen Magnum Region
}

\author{
Maria-Eleni Chovalopoulou and Andreas Bertsatos \\ Department of Animal and Human Physiology, Faculty of Biology, School of Sciences, University of Athens, \\ Panepistimiopolis, 15781 Athens, Greece
}

Correspondence should be addressed to Maria-Eleni Chovalopoulou; marilenachov@biol.uoa.gr

Received 2 March 2017; Revised 28 May 2017; Accepted 3 July 2017; Published 31 July 2017

Academic Editor: Hugo Cardoso

Copyright (C) 2017 Maria-Eleni Chovalopoulou and Andreas Bertsatos. This is an open access article distributed under the Creative Commons Attribution License, which permits unrestricted use, distribution, and reproduction in any medium, provided the original work is properly cited.

\begin{abstract}
Sex determination is one of the principal aims when examining human skeletal remains. One method for sex determination is based on metric criteria using discriminant functions. However, discriminant function sexing formulas are population-specific. In the present study, we determined the use of the foramen magnum as well as the occipital condyles for sex determination on adults from a modern Greek population. Seven parameters were examined (4 obtained from the foramen magnum; 3 obtained from the occipital condyles) and the sample consisted of 154 adult crania ( 77 males and 77 females). The results indicate that the foramen magnum region exhibits sexual dimorphism and the mean values for all parameters were higher in males than females. In comparison, the occipital condyles provide a higher determination of the correct sex than the foramen magnum. The combination of the occipital condyle variables allowed for the development of discriminant functions that predicted the correct sex in $74 \%$ of all cases. Finally, although other anatomical regions can discriminate the sexes with higher accuracy, the functions developed in this study could be cautiously used in cases of fragmented crania.
\end{abstract}

\section{Introduction}

Reliable sex determination is one of the principal aims when examining human skeletal remains. In forensics or anthropology, the occipital bone is frequently used in sex determination because the cranial base tends to withstand both physical insults and inhumation more successfully than many other areas of the cranium [1].

There are two major methods for sex determination from the cranium. The first one is based on morphological criteria [2-4]. The roughness of the nuchal lines and the prominence of the external occipital protuberance are good indicators for the qualitative diagnosis of sex [5]. The second one is based on metric criteria using discriminant functions $[6,7]$. The dimensions of the occipital condyles and the foramen magnum have been reported as useful for quantitative diagnosis of sex by several authors [8-10]. According to Gapert and his colleagues [11], the correctly classified crania ranged from $65.8 \%$ for univariate functions to $70.3 \%$ for multivariate functions. Gapert and his colleagues [11] evaluated the foramen magnum of eighteenth and nineteenth century
British adult skulls. However, discriminant functions should be used only when the individual is known to come from the same population from which the functions were derived $[12,13]$, since sexual dimorphism is population-specific [14].

The aim of the present study is to assess the use of the foramen magnum as well as the occipital condyles for sex determination on adults by developing discriminant functions for a modern Greek population. Previous research regarding the foramen magnum region in a Greek population was conducted by Natsis and his colleagues in 2013 [15]. Natsis and his colleagues [15] classified the foramen magnum region according to its shape and they investigated possible correlations between anatomic metric values and various parameters. According to their results, the foramen magnum region exhibits sexual dimorphism.

\section{Material and Methods}

The sample consisted of 154 adult crania of Greek individuals of known sex and age at death: 77 males and 77 females. These crania constitute part of the modern skeletal reference 


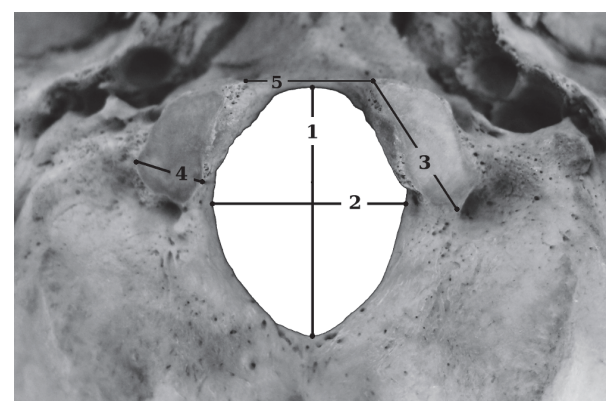

FIGURE 1: Foramen magnum region parameters. (1) FML: foramen magnum length; (2) FMB: foramen magnum breadth; (3) OCL: occipital condyle length; (4) OCB: occipital condyle breadth; (5) MID: minimum intercondylar distance.

collection (known as the Athens Collection) housed in the Department of Animal and Human Physiology (Faculty of Biology, National and Kapodistrian University of Athens). All individuals are Greek nationals who died in Athens and were buried and then exhumed from local cemeteries. The age at death of the individuals ranges from 19 to 99 years old and their year of birth from 1879 to 1965 . Year of death for all individuals ranges between 1960 and 1996, while the place of birth covers the entire country. Individuals without any evidence of trauma or dysmorphism were selected. The parameters examined were as follows:

(1) The foramen magnum length (FML) direct distance from basion to opisthion

(2) The foramen magnum breadth (FMB) maximum distance between the lateral margins of foramen magnum

(3) The foramen magnum index (FMI) calculated using the formula: $(\mathrm{FMB} \times 100) / \mathrm{FML}$

(4) The foramen magnum area (FMA) calculated using Radinsky's [16] formula: $(1 / 4) \times \pi \times \mathrm{FMB} \times \mathrm{FML}$

(5) The occipital condyle length (OCL) direct distance along the long axis from the most anterior to the most posterior point on the margin of the occipital condyle

(6) The occipital condyle breadth (OCB) direct distance perpendicular to the long axis from the most lateral to the most medial point on the margin of the occipital condyle

(7) The minimum intercondylar distance (MID) direct distance from the most medial point on the margin of the left occipital condyle to the most medial point on the margin of the right occipital condyle

The 3D coordinates of the foramen magnum region were collected using an Immersion Corporation MicroScribe 3DX digitizer with a standard error of $0.23 \mathrm{~mm}$. Microsoft Excel was used with MicroScribe 3DX to obtain the coordinates $(x, y, z)$ of each landmark and to calculate the equivalent interlandmark distances (Figure 1).

Initially, descriptive statistics (mean, standard deviation) were carried out for each parameter. Additionally, regarding the occipital condyles parameters, an independent samples $t$ test was performed in order to ascertain whether any bilateral asymmetry exists. Finally, to analyze sex differences, independent samples $t$-test and discriminant function analysis (DFA) were used. The DFA was calculated for all parameters. However, the foramen magnum index as well as the area of the foramen magnum was not combined with the foramen magnum length or breadth, since a DFA is optimal when few of the single variables correlate.

All the statistical analyses were performed using the Statistical Package for Social Sciences (IBM SPSS version 23.0, Armonk, NY).

\section{Results and Discussion}

3.1. Results. The results of the descriptive statistics are presented in Table 1 . The mean values for all parameters were higher in males than females. All data were normally distributed according to the results of the Shapiro-Wilk test. Consequently, a parametric test was performed in order to ascertain whether any bilateral asymmetry exists regarding the dimensions of the occipital condyles and to analyze sex differences. According to Table 2, no statistically significant difference between right and left side was found in either the occipital condyle length or the occipital condyle breadth. Therefore, the averages of the distances obtained from both sides were used in the subsequent analysis.

The results shown in Table 3 indicate that, with the exception of the foramen magnum index, all parameters are influenced by sex $(p<0.05)$. The discriminant functions for each single parameter and five possible combinations of them are given in Table 4 . Additionally, Table 4 shows the results of the cross-validation based on "leave-one-out" principle. The most reliable single parameter for sex determination was the occipital condyle length (69.5\%) followed by Radinsky's area $(66.9 \%)$. Finally, the minimum intercondylar distance combined with the occipital condyle length as well as the occipital condyle breadth proved to be the best combination of parameters regarding sex determination (74.0\%) followed by the combination of Radinsky's area, the occipital condyle length, and the occipital condyle breadth (72.1\%).

3.2. Discussion. Regarding the nonexistence of bilateral asymmetry of the occipital condyles, our results are in agreement with those of other populations [17, 18]. Additionally, the present study confirms the results of Natsis and his colleagues [15] regarding the presence of sexual dimorphism in the foramen magnum region in the modern Greek population. Natsis and his colleagues' [15] sample included skulls of unknown age, mainly from the collection of the Departments of Anatomy of Aristotle University (Thessaloniki). On the other hand, all the individuals we examined were acquired from cemeteries in the Athens area with known age at death and year of birth. The mean values of length and width of the foramen magnum and the mean value of breadth of the occipital condyle of our sample are similar to Natsis and his colleagues sample. However, when comparing the mean values of the length of the occipital condyle and minimum intercondylar distance, our sample shows smaller and bigger 
TABLE 1: Descriptive statistics: dimensions, index, and area of the foramen magnum and the occipital condyles (in $\mathrm{mm}$ ).

\begin{tabular}{|c|c|c|c|c|}
\hline & Mean & Std. deviation & Minimum & Maximum \\
\hline \multicolumn{5}{|l|}{ FMB } \\
\hline Male & 32.48 & 2.70 & 26.92 & 40.01 \\
\hline Female & 30.62 & 2.18 & 24.80 & 36.52 \\
\hline \multicolumn{5}{|l|}{ FML } \\
\hline Male & 36.69 & 2.47 & 30.02 & 42.18 \\
\hline Female & 34.87 & 2.41 & 27.97 & 40.98 \\
\hline \multicolumn{5}{|l|}{ FMI } \\
\hline Male & 88.70 & 6.87 & 74.43 & 104.55 \\
\hline Female & 88.04 & 6.76 & 75.73 & 108.67 \\
\hline \multicolumn{5}{|l|}{ FMA } \\
\hline Male & 938.12 & 123.20 & 669.14 & 1238.50 \\
\hline Female & 839.82 & 99.91 & 613.63 & 1144.62 \\
\hline \multicolumn{5}{|l|}{ OCL-left } \\
\hline Male & 24.36 & 2.68 & 17.76 & 30.83 \\
\hline Female & 22.21 & 2.33 & 16.41 & 26.57 \\
\hline \multicolumn{5}{|l|}{ OCL-right } \\
\hline Male & 24.52 & 3.07 & 16.43 & 30.46 \\
\hline Female & 22.51 & 2.41 & 15.51 & 28.46 \\
\hline \multicolumn{5}{|l|}{ OCB-left } \\
\hline Male & 13.99 & 1.96 & 10.03 & 20.37 \\
\hline Female & 13.17 & 1.84 & 9.14 & 17.72 \\
\hline \multicolumn{5}{|l|}{ OCB-right } \\
\hline Male & 13.80 & 1.92 & 10.33 & 18.68 \\
\hline Female & 12.76 & 1.76 & 8.78 & 17.51 \\
\hline \multicolumn{5}{|l|}{ MID } \\
\hline Male & 24.28 & 3.01 & 15.95 & 32.53 \\
\hline Female & 22.21 & 2.58 & 16.34 & 28.06 \\
\hline
\end{tabular}

TABle 2: Mean differences in dimensions of the occipital condyles between right and left side.

\begin{tabular}{lccc}
\hline & $t$ & $\mathrm{df}$ & Sig. (2-tailed) \\
\hline OCL & & & \\
Male & -.347 & 152 & .729 \\
$\quad$ Female & -.795 & 152 & .428 \\
OCB & & & \\
Male & .607 & 152 & .545 \\
Female & 1.415 & 152 & .159 \\
\hline
\end{tabular}

$p$ value $\leq 0.05$ is accepted as statistically significant.

values, respectively (Table 5). According to our observations, there might be variation in the occipital condyles among different parts of Greece.

Comparison of the distance parameters in different populations is given in Table 5. When observing the description of the foramen magnum length and the foramen magnum breadth, the modern Greek population seems to show similar values for males and females, as the Turkish $[19,20]$, British
TABlE 3: Mean differences of the parameters of the foramen magnum and the occipital condyle between males and females.

\begin{tabular}{lccc}
\hline & $t$ & $\mathrm{df}$ & Sig. (2-tailed) \\
\hline FMB & $4.716^{*}$ & 152 & .000 \\
FML & $4.626^{*}$ & 152 & .000 \\
FMI & .592 & 152 & .554 \\
FMA & $5.438^{*}$ & 152 & .000 \\
OCL & $5.326^{*}$ & 152 & .000 \\
OCB & $3.410^{*}$ & 152 & .001 \\
MID & $4.522^{*}$ & 152 & .000 \\
\hline
\end{tabular}

${ }^{*}$ Parameters are significant at the 0.05 level.

[11], and Spanish [21] populations. The Indian [22] population, especially the Indian females, seems to show smaller values, when compared to the aforementioned populations.

In regard to the occipital condyle variables, the Greek population has higher OCB value than the European American [23], the African American [23], the Turkish [20], and the British [24] populations. According to Uysal and her colleagues [20], the Turkish population demonstrates by far 
TABLE 4: Discriminant function (DF) equations for the foramen magnum region.

\begin{tabular}{|c|c|c|c|c|c|c|}
\hline \multirow{3}{*}{$\begin{array}{l}\text { Variables } \\
\text { FMB }\end{array}$} & \multirow{3}{*}{$\begin{array}{c}\text { Wilk's lambda } \\
0.872\end{array}$} & \multirow{3}{*}{$\begin{array}{c}x 2 \\
20.689\end{array}$} & \multirow{3}{*}{$\begin{array}{c}\text { Sig. } \\
0.000\end{array}$} & \multicolumn{2}{|c|}{ Function coefficients } & \multirow{3}{*}{$\begin{array}{c}\text { Cross-validation }^{*} \text { hit ratio } \\
65.6 \%\end{array}$} \\
\hline & & & & Constant & -12.851 & \\
\hline & & & & FMB & 0.407 & \\
\hline \multirow{2}{*}{ FML } & \multirow{2}{*}{0.877} & \multirow{2}{*}{19.955} & \multirow{2}{*}{0.000} & Constant & -14.658 & \multirow{2}{*}{$63.6 \%$} \\
\hline & & & & FML & 0.410 & \\
\hline \multirow{2}{*}{ FMA } & \multirow{2}{*}{0.837} & \multirow{2}{*}{26.932} & \multirow{2}{*}{0.000} & Constant & -7.926 & \multirow{2}{*}{$66.9 \%$} \\
\hline & & & & FM area & 0.009 & \\
\hline \multirow{3}{*}{$\mathrm{FMB}+\mathrm{FML}$} & \multirow{3}{*}{0.836} & \multirow{3}{*}{26.980} & \multirow{3}{*}{0.000} & Constant & -16.026 & \multirow{3}{*}{$65.6 \%$} \\
\hline & & & & FMB & 0.244 & \\
\hline & & & & FML & 0.233 & \\
\hline \multirow{2}{*}{ OCL } & \multirow{2}{*}{0.843} & \multirow{2}{*}{25.924} & \multirow{2}{*}{0.000} & Constant & -9.670 & \multirow{2}{*}{$69.5 \%$} \\
\hline & & & & OCL & 0.413 & \\
\hline \multirow{2}{*}{$\mathrm{OCB}$} & \multirow{2}{*}{0.929} & \multirow{2}{*}{11.170} & \multirow{2}{*}{0.001} & Constant & -7.954 & $57.1 \%$ \\
\hline & & & & $\mathrm{OCB}$ & 0.592 & $57.1 \%$ \\
\hline MID & 0881 & 19124 & 0000 & Constant & -8.199 & $64.3 \%$ \\
\hline NHID & 0.001 & 19.124 & 0.000 & MID & 0.353 & $04.5 \%$ \\
\hline & & & & Constant & -10.616 & \\
\hline $\mathrm{OCL}+\mathrm{OCB}$ & 0.831 & 27.884 & 0.000 & OCL & 0.350 & $67.5 \%$ \\
\hline & & & & $\mathrm{OCB}$ & 0.180 & \\
\hline & & & & Constant & -15.026 & \\
\hline $\mathrm{OCL}+\mathrm{OCB}+\mathrm{MID}$ & 0698 & 54.052 & 0000 & OCL & 0.317 & $740 \%$ \\
\hline$U C L+U C D+M H D$ & 0.098 & 54.032 & 0.000 & OCB & 0.108 & $74.0 \%$ \\
\hline & & & & MID & 0.265 & \\
\hline & & & & Constant & -12.167 & \\
\hline $\mathrm{FMA}+\mathrm{OCL}+\mathrm{OCB}$ & 0753 & 42693 & 0000 & FM area & 0.006 & $721 \%$ \\
\hline FMA + UCL + UCD & 0.753 & 42.090 & 0.000 & OCL & 0.176 & $/ 2.1 \%$ \\
\hline & & & & OCB & 0.211 & \\
\hline & & & & Constant & -15.113 & \\
\hline & & & & FM area & 0.003 & \\
\hline $\mathrm{FMA}+\mathrm{OCL}+\mathrm{OCB}+\mathrm{MID}$ & 0.681 & 57.681 & 0.000 & OCL & 0.244 & $71.4 \%$ \\
\hline & & & & OCB & 0.140 & \\
\hline & & & & MID & 0.214 & \\
\hline
\end{tabular}

* Based on "leave-one-out" principle. $p$ value $\leq 0.05$ is accepted as statistically significant.

the lowest values of MID. The extreme values for MID in Uysal et al.s [20] paper suggests an error in reporting or a typo in the final manuscript. Finally, according to our results, the Greek population has similar OCL value with the European American [23] and the British [24] populations.

In the Greek population, the best determination of the correct sex, regarding the foramen magnum variables, was achieved through the foramen magnum area (66.9\%), while the combination of the foramen magnum variables achieved only $65.6 \%$ (Table 4 ). In comparison, the occipital condyles provide a higher determination of the correct sex than the foramen magnum. The combination of the occipital condyle variables allowed for the development of discriminant functions that predicted the correct sex in $74 \%$ of all cases, while the best single variable (OCL) achieved 69.5\%. These relatively low classification accuracies reflect the low amount of sexual dimorphism and indicate that these variables should be used with caution when attempting to estimate sex.
The low degree of sexual dimorphic expression within the foramen magnum may be explained by the fact that it reaches the end of growth rather early in childhood [25]. Therefore, no significant secondary sexual changes are expected to develop. Additionally, the prime function of the foramen magnum is to transmit the medulla oblongata and its membranes as well as the spinal component of the accessory nerve into the skull and no muscles act upon its shape and size. Although sex differences of the occipital condyles, whose prime function are to enable the head to move relative to the cervical vertebral column, are low compared to other anatomical regions [26], they are still higher when compared to the foramen magnum. The cranial base's cartilages are known to resist compression [27] and the atlantooccipital joint is primarily under static strain [28]. However, although loading stresses do not seem to play a major role in influencing dimorphic expression in the occipital condyle, the biomechanical function of the craniocervical joint could be 


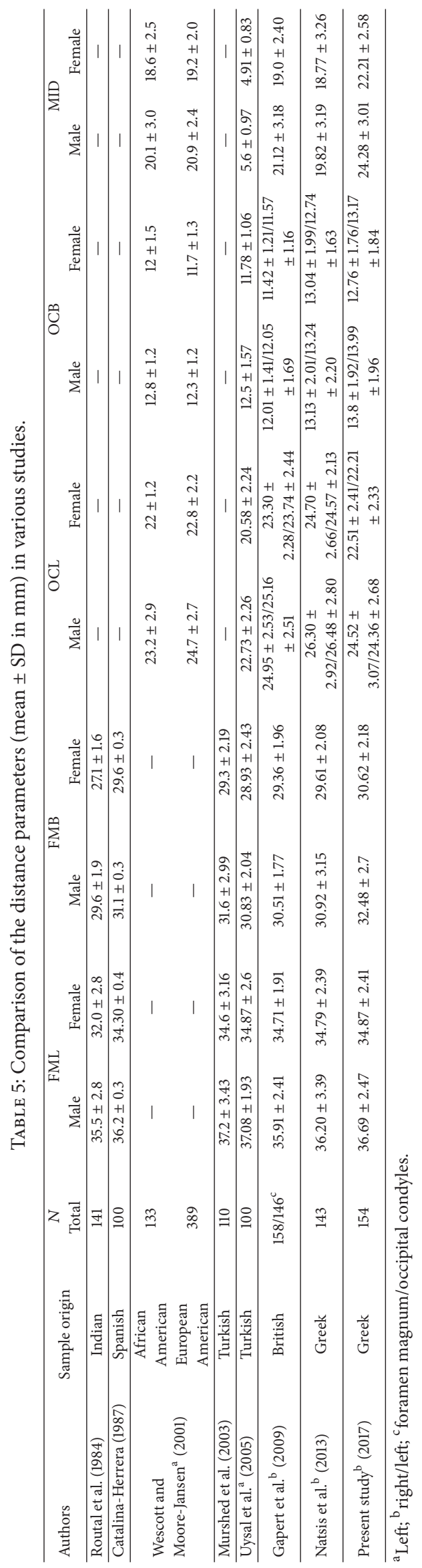


one reason for the increased expression of sex dimorphism in occipital condyles when compared to the foramen magnum. According to Gapert and his colleagues [24], it is more likely that the expression of sexual dimorphism in the occipital condyles is mainly due to genetic rather than epigenetic factors. Therefore, it is important to know the origin of any unidentified skull in order to choose the appropriate population-specific discriminant function formula for estimating sex.

\section{Conclusions}

This study confirms that the foramen magnum region exhibits sexual dimorphism; however, the dimorphic expression is low to moderate. Although other anatomical regions, such as the pelvis, can discriminate between sexes with higher accuracy, the functions developed in this study could be used in cases of fragmented cranial remains. Finally, since the discriminant function sexing formulas are population-specific, this method should be applied on samples that belong to Greek populations or at least to populations with similar expression of sexual dimorphism in the foramen magnum region. Because error rates are expected to be relatively high ( $26 \%$ or higher), sex estimation using these discriminant functions should be done with extreme caution.

\section{Conflicts of Interest}

The authors declare that there are no conflicts of interest regarding the publication of this paper.

\section{References}

[1] M. Graw, "Morphometrische and Morphognostische. Geschlecthsdiagnostik an der menschlichen Schadelbasis," in Osteologische Identifikation and Altersschatzung., Lubeck: SchmidtRomhild, M. Oehmicen and G. Geserick, Eds., pp. 103-121, 2001.

[2] J. Bruzek, "A method for visual determination of sex, using the human hip bone," The American Journal of Physical Anthropology, vol. 117, no. 2, pp. 157-168, 2002.

[3] J. E. Buikstra and D. H. Ubelaker, Standards for Data Collection from Human Skeletal Remains, Arkansas Archaeological Survey, Fayetteville, North Carolina, 1994.

[4] D. E. Walrath, P. Turner, and J. Bruzek, "Reliability test of the visual assessment of cranial traits for sex determination," American Journal of Physical Anthropology, vol. 125, no. 2, pp. 132-137, 2004.

[5] T. L. Rogers, "Determining the sex of human remains through cranial morphology," Journal of Forensic Sciences, vol. 50, no. 3 , pp. 493-500, 2005.

[6] E. Giles and O. Elliot, "Sex determination by discriminant function analysis of crania," American Journal of Physical Anthropology, vol. 21, no. 1, pp. 53-68, 1963.

[7] P. L. Walker, "Sexing skulls using discriminant function analysis of visually assessed traits," American Journal of Physical Anthropology, vol. 136, no. 1, pp. 39-50, 2008.

[8] F. Ferreira, B. Rosenberg, and H. P. da Luz, "The Foramen Magnum index in brazilians," Revista da Faculdade de Odontologia da Universidade de Sao Paulo, vol. 5, no. 4, pp. 297-302, 1967.
[9] I. N. Zadvornov, "Variations in the shape of the foramen magnum and the structure of its posterior border," Arkhiv Anatomii, Gistologii I Embriologii, vol. 63, no. 7, pp. 42-50, 1972.

[10] W. R. Teixeira, "Sex identification utilizing the size of the foramen magnum," The American Journal of Forensic Medicine and Pathology, vol. 3, no. 3, pp. 203-206, 1982.

[11] R. Gapert, S. Black, and J. Last, "Sex determination from the foramen magnum: discriminant function analysis in an eighteenth and nineteenth century British sample," International Journal of Legal Medicine, vol. 123, no. 1, pp. 25-33, 2009.

[12] D. H. Ubelaker, A. H. Ross, and S. M. Graver, "Application of forensic discriminant functions to a spanish cranial sample," Forensic Sci Commun 4, 2002, http://www.fbi.gov/hq/lab/fsc/ backissu/july2002/ubelaker1.htm.

[13] F. Ramsthaler, K. Kreutz, and M. A. Verhoff, "Accuracy of metric sex analysis of skeletal remains using Fordisc ${ }^{\circledR}$ based on a recent skull collection," International Journal of Legal Medicine, vol. 121, no. 6, pp. 477-482, 2007.

[14] F. W. Rösing, M. Graw, B. Marré et al., "Recommendations for the forensic diagnosis of sex and age from skeletons," HOMOJournal of Comparative Human Biology, vol. 58, no. 1, pp. 75-89, 2007.

[15] K. Natsis, M. Piagkou, G. Skotsimara, G. Piagkos, and P. Skandalakis, "A morphometric anatomical and comparative study of the foramen magnum region in a Greek population," Surgical and Radiologic Anatomy, vol. 35, no. 10, pp. 925-934, 2013.

[16] L. Radinsky, "Relative brain size: A new measure," Science, vol. 155, no. 3764, pp. 836-838, 1967.

[17] E. D. Kizilkanat, N. Boyan, R. Soames, and O. Oguz, "Morphometry of the hypoglossal canal, occipital condyle, and foramen magnum," Neurosurgery Quarterly, vol. 16, no. 3, pp. 121125, 2006.

[18] V. C. Chancey, D. Ottaviano, B. S. Myers, and R. W. Nightingale, "A kinematic and anthropometric study of the upper cervical spine and the occipital condyles," Journal of Biomechanics, vol. 40, no. 9, pp. 1953-1959, 2007.

[19] K. A. Murshed, A. E. Cicekcibasi, and I. Tuncer, "Morphometric evaluation of the foramen magnum and variations in its shape: a study on computerized tomographic images of normal adults," Turkish Journal of Medical Science, vol. 33, pp. 301-306, 2003.

[20] S. R. M. Uysal, D. Gokharman, M. Kacar, I. Tuncbilek, and U. Kosar, "Estimation of Sex by 3D CT Measurements of the Foramen Magnum," Journal of Forensic Sciences, vol. 50, no. 6, pp. 1310-1314, 2005.

[21] C. J. Catalina-Herrera, "Study of the anatomic metric values of the foramen magnum and its relation to sex," Acta Anatomica, vol. 130, no. 4, pp. 344-347, 1987.

[22] R. R. Routal, G. P. Pal, S. S. Bhagwat, and B. P. Tamankar, "Metrical studies with sexual dimorphism in foramen magnum of human crania," Journal of the Anatomical Society of India, vol. 2, no. 33, pp. 85-89, 1984.

[23] D. J. Wescott and P. H. Moore-Jansen, "Metric variation in the human occipital bone: forensic anthropological applications," Journal of Forensic Sciences, vol. 46, no. 5, pp. 1159-1163, 2001.

[24] R. Gapert, S. Black, and J. Last, "Sex determination from the occipital condyle: Discriminant function analysis in an eighteenth and nineteenth century british sample," American Journal of Physical Anthropology, vol. 138, no. 4, pp. 384-394, 2009.

[25] L. Scheuer and S. M. Black, The juvenile skeleton, Elsevier Academic Press, London, UK, 2004. 
[26] J. Bruzek and P. Murail, "Methodology and reliability of sex determination from the skeleton," in Forensic Anthropology and Medicine: Complementary Sciences From Recovery to Cause of Death. Springer e-Books, A. Schmitt, E. Cunha, and J. Pinheiro, Eds., pp. 225-242, Humana Press, Totowa, New Jersey, USA, 2006.

[27] C. S. Larsen, Bioarcheology, Interpreting Behavior from The Human Skeleton, Cambridge University Press, 2003.

[28] H. Wolff, "Anmerkungen zur Pathophysiologie der Funktionsstörungen des Kopfgelenkbereiches," in Der kraniozervikale Übergang, M. Hülse, Ed., Aktuelle, 1998. 


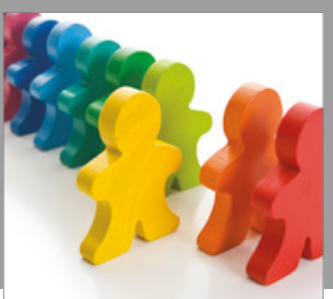

Autism

Research and Treatment
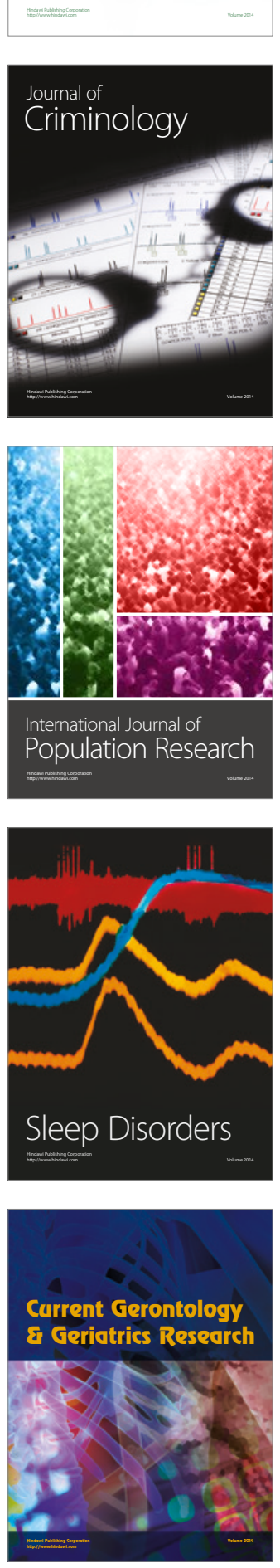

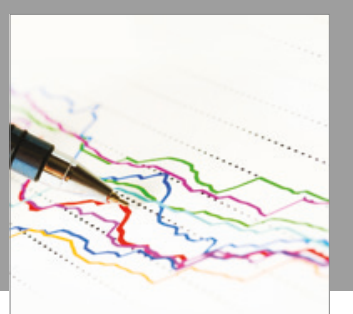

Economics

Research International

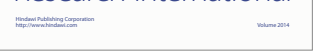

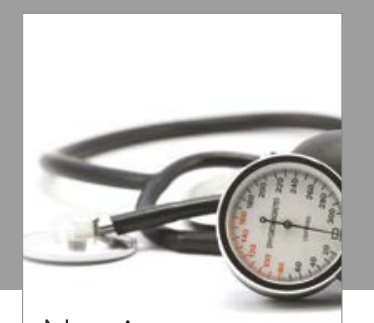

Nursing

Research and Practice

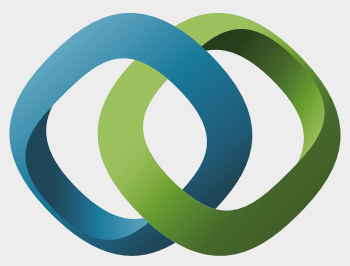

\section{Hindawi}

Submit your manuscripts at

https://www.hindawi.com
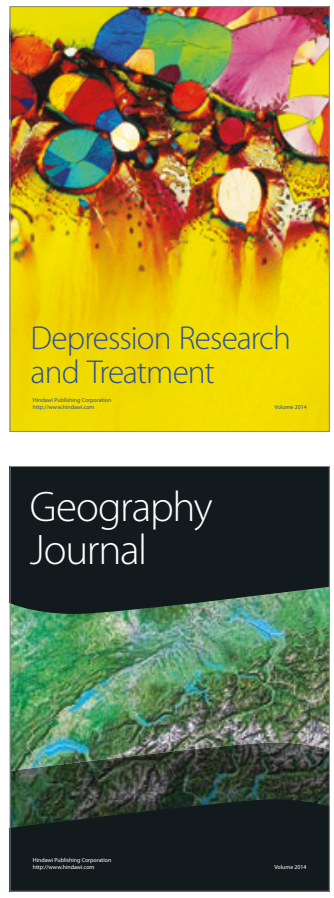
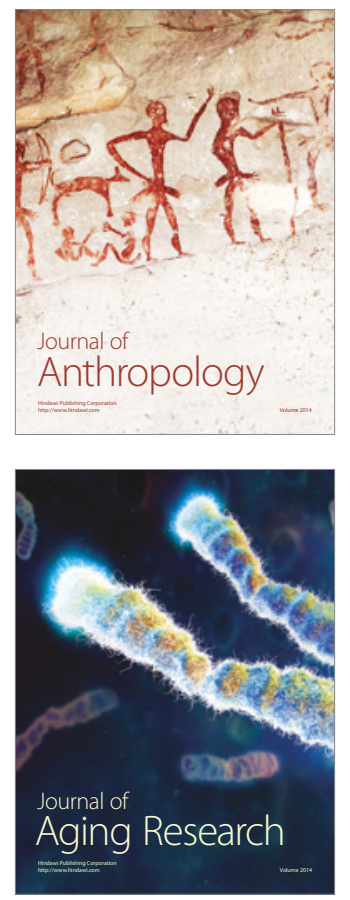
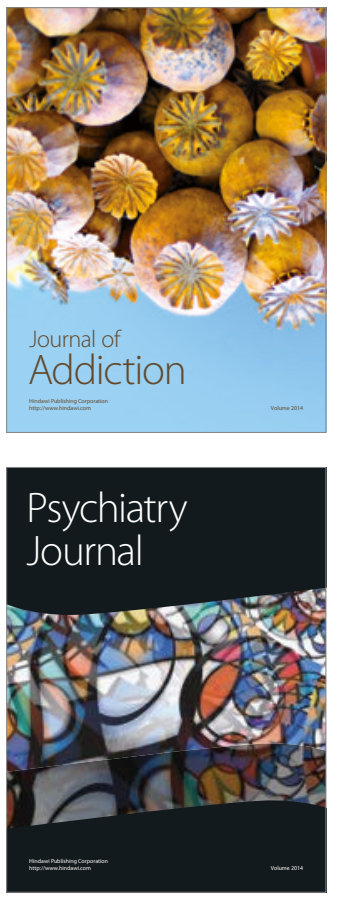

Child Development

Research

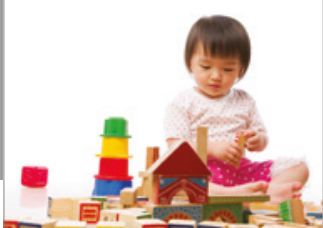

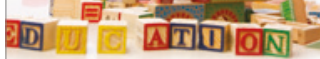
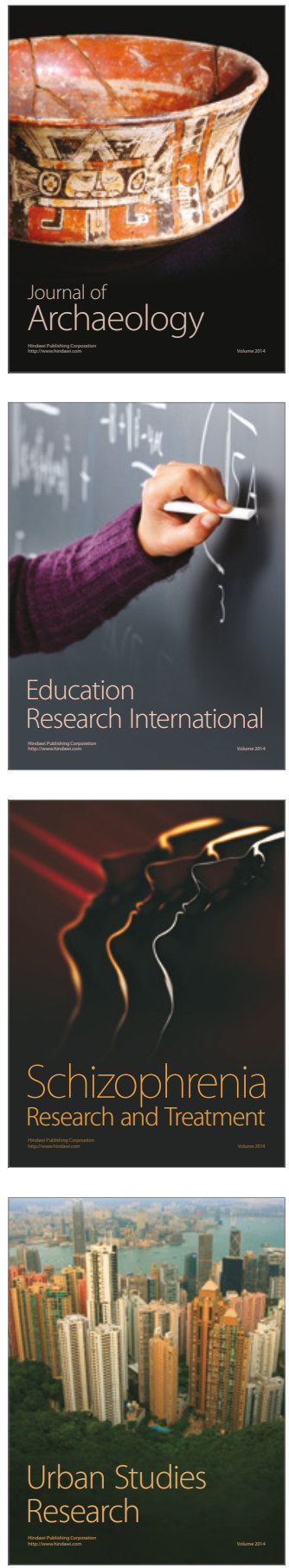